\title{
The Impact of an Integrated Robotics STEM Course with a Sailboat Topic on High School Students' Perceptions of Integrative STEM, Interest, and Career Orientation
}

\author{
Yiching Chen ${ }^{1}$, Chi-Cheng Chang ${ }^{1 *}$ \\ ${ }^{1}$ Department of Technology Application and Human Resource Development, National Taiwan Normal University, Taipei, \\ TAIWAN
}

Received 20 March 2018 - Revised 19 June 2018 - Accepted 16 July 2018

\begin{abstract}
The robotics curriculum is one of the most common and popular curricula for stimulating students' interest in the science, technology, engineering, and mathematics (STEM) disciplines. The purpose of this study was to develop a robotics curriculum that highly integrates STEM and uses open software and hardware, and to test its effects on high school students' learning outcomes, interest, and perceptions of STEM. The study involved 82 Grade 10 students; divided into two groups, the experimental group experienced an integrated robotics STEM course, whereas the comparison group participated in a curriculum with commercial robotics. After a semester, the quantitative and qualitative data showed that the experimental group reported significantly more positive perceptions of integrated STEM, with strengthened knowledge, interest, and career orientation towards related fields. The findings of this study provide suggestions for STEM curriculum development.
\end{abstract}

Keywords: Arduino, robot, robotics curriculum, STEM curriculum, STEM education

\section{INTRODUCTION}

Since the 1980s, robots have been used in education, especially in primary and secondary education (Altin \& Pedaste, 2013). Ideally, when building robots, students apply their knowledge of scientific inquiry, mathematical calculations, and other technologies; this process helps to foster their problem-solving ability from multiple angles (Avsec, Rihtaršič, \& Kocijancic, 2014; Doerschuk, Bahrim, Daniel, Kruger, Mann, \& Martin, 2016). Some scholars have found that students think taking robotics courses helps them to develop hands-on skills, and more knowledge in science, technology, engineering, and mathematics (STEM) (Abdel-Salam, Sawaf, \& Williamson, 2009; Sullivan \& Heffernan, 2016). English (2016) developed an integrated STEM framework which links learning objectives and learning activities between different STEM disciplines. Doerschuk et al. (2016) also confirmed that through handson robotics course, students increase their interest in STEM and career advancement. In general, students have evinced interest in robots, making robotics education popular in STEM areas (Rihtaršič, Avsec, \& Kocijancic, 2016).

In recent years, developed countries in Europe and the United States have been promoting the integration of STEM programs in schools to strengthen students' competence in scientific inquiry and problem solving, and to prepare students for future industrial demands (Bybee, 2013), which is crucial to national competitiveness (Kennedy \& Odell, 2014). Researchers have found that robotics STEM courses can lead to a significant increase in positive attitudes toward STEM (Doerschuk et al., 2016; Nugent, Barker, Grandgenett, \& Adamchuk, 2010), and in test scores in science (Mitnik, Nussbaum \& Recabaarren, 2009; Williams, Ma, Prejean, Ford, \& Lai, 2008) and mathematics (Hussain, Lindh \& Shukur, 2006; Somyurek, 2015). However, significant correlation has yet to be established between STEM and students' learning outcomes in areas such as mathematics, geospatial concepts, or computer programming (Nugent et al., 2010). There is thus room for improvement in the curriculum.

Therefore, the aim of this study is to develop a robotics course that highly integrates the subject of STEM, and to test its effects on high school students' learning outcomes, interest, and perceptions of STEM.

(C) 2018 by the authors; licensee Modestum Ltd., UK. This article is an open access article distributed under the terms and conditions of the Creative Commons Attribution License (http://creativecommons.org/licenses/by/4.0/). \smartsofia@gmail.com $\square$ samchang@ntnu.edu.tw (*Correspondence) 


\section{Contribution of this paper to the literature}

- This study demonstrated that a group with STEM integration could significantly outperform another group learning with commercial robotics, regarding perceptions of the integration of STEM, interest, and career orientation towards STEM, and STEM knowledge.

- This study provided an example to implement a robotics curriculum with integrated STEM using a single topic, a robotic sailboat, by adopting Arduino Uno.

- This study demonstrated a task-oriented teaching strategy for the pedagogy in STEM education.

\section{RESEARCH QUESTIONS}

Four main research questions are explored in this study:

- How does the integrated STEM course affect students' perceptions of the integrated disciplines?

- How does the integrated STEM course affect students' STEM interest and their career orientations?

- To what degree are the students satisfied with the integrated STEM course?

- What effect does the integrated STEM course have on students' knowledge of the STEM disciplines?

\section{LITERATURE REVIEW}

\section{Robots in the STEM Curriculum}

A robot is a product of the interplay of science, technology, and engineering. It can be used to understand the integration of knowledge in STEM fields (Alimisis, 2013; Avesc et al., 2014; Benitti, 2012). The robot market is growing since more and more schools are interested in the use of robots for teaching and learning (Rusk, Resnick, Berg, \& Pezalla-Granlund, 2008). Robots from different companies are made available for learners to assemble components manually, such as LEGO $^{\circledR}$, Fischertechnik, Arduino, and Raspberry (Araújo, Portugal, Couceiro, \& Rocha, 2015; Avesc et al., 2014). Based on a review of the existing curricula and literature, researchers have pointed out that robotics courses mostly focus on robot mechanical structures, electronic parts, programming, and engineering design (Alimisis, 2013; Benitti, 2012; Seul, 2013; Slangen, van Keulen, \& Gravemeijer, 2011), and the introduction and illustration of the use of the components and the assembly of the mechanical structures normally takes much time in class (Avsec et al., 2014).

In addition, students spend a considerable amount time on trial and error and coding design while building robots (Barak \& Zadok, 2007; Gaudiello \& Zibetti, 2013; Sullivan \& Lin, 2012; Williams et al., 2008). Their trials, however, tend to be unsystematic as they lack controlled variables, and it is difficult for them to figure out how robots work (Gaudiello \& Zibetti, 2013; Sullivan \& Lin, 2012). These practices seem to be lacking in scientific inquiry (Bers, Flannery, Kazakoff, \& Sullivan, 2014; Sullivan \& Lin, 2012; Sullivan \& Moriarty, 2009; Williams et al., 2008). Likewise, science and mathematics are less emphasized or integrated into the curriculum (Bers et al., 2014; Sullivan \& Lin, 2012; Williams et al., 2008). Robotics courses mostly emphasize programming or robot assembly but lack knowledge integration of STEM disciplines (Benitti, 2012). Moreover, Alimisis (2013), Altin and Pedaste (2013) and Benitti (2012) reviewed the literature on robotics education for the past 10 years, and found that few studies had drawn on the learning outcomes; even fewer had examined all four STEM disciplines. Rather, most of the research discusses students' skills of robotics or attitudes towards robotics education. Alimisis (2013) and Benitti (2012) proposed that the robotics curriculum should be effectively integrated with other disciplines, and stated that there is a need for the development of appropriate robotics curricula and teaching strategies.

\section{The Effectiveness of Robotics STEM Curricula}

To design a robot, students need knowledge of constructing stable mechanical structures, electronic circuits, computer programming, and debugging (Barak \& Zadok, 2007). A well-designed robotics curriculum should include computer programming, problem solving, computing thinking, and instruction of science and mathematics. Many studies have shown promising evidence of the effectiveness of robotics curricula. For example, Abdel-Salam et al. (2009) found that $88 \%$ of students thought that taking robotics courses would help them develop hands-on skills, and $83 \%$ believed that they learned more about STEM through robotics courses.

Previous studies have provided empirical evidence of the effectiveness of robotics curricula on knowledge acquisition, high order cognitive ability, attitudes, and hands-on operation. First, robotics courses improve students' science (Benitti, 2012; Mitnik et al., 2009; Williams et al., 2008), engineering, technology (Barker \& Ansorge, 2007), mathematics (Eguchi, 2016; Hussain et al., 2006; Nugent et al., 2010; Somyurek, 2015), and computer 
programming (Nugent et al., 2010; Slangen et al., 2011; Sullivan \& Lin, 2012). However, Nugent et al. (2010) and Nugent, Barker, and Grandgenett (2012) found that, despite a significant increase in students' learning attitudes towards STEM in robotics STEM courses, there were no significant results of learning outcomes in mathematics, geospatial concepts, or computer programming.

Second, many studies have indicated that robotics courses could increase students' ability to conduct scientific inquiry through exploring, thinking, and interacting with robots in real situations (Jojoa, Bravo, \& Cortes, 2010; Williams et al., 2008). The robotics platform also encourages problem solving through solving real problems in conditional situations, as students have to apply knowledge and skills to find a solution and make a robot to solve a problem (Jojoa et al., 2010; Nugent, Barker, Grandgenett, \& Welch, 2016). It also facilitates critical thinking during the challenge process of a robotics competition, as students have to think up and make a robot to compete via teamwork (Eguchi, 2016; Park \& Kim, 2011). Robotics is a multidisciplinary field naturally appealing to young people because of its "real," hands-on, programmable, and direct interaction features. Research has shown that students not only have fun working with robotics in real situations, they also have positive learning outcomes (Benitti, 2012).

Third, there is a shortage of human resources in the technology-related sectors. Becker and Park (2011) indicated that STEM education needed reforms to retain students in these fields. With the decrease in the number of STEM college graduates, researchers have been seeking ways to retain students majoring in STEM so that they are better prepared to enter the science and technology industries (Cristoforis, Pedre, Nitsche, Fischer, Pessacg, \& Pietro, 2013; López-Rodríguez \& Cuesta, 2016). Increased efforts have been made to reform STEM education from early childhood to college level, mainly through incorporating new technologies as well as project-based learning activities (Hagedorn \& Purnamasari, 2012). Engineering-designed tasks can stimulate students' interest and engagement in STEM (Hernandez et al., 2014). Furthermore, robotics STEM curricula can promote secondary school students' awareness of, interest in (Abaid, Kopman, \& Porfiri, 2013; Cristoforis et al., 2013; Doerschuk et al., 2016; Jojoa et al., 2010), and careers in STEM (Cristoforis et al., 2013). Finally, robotics courses can provide opportunities for learning by doing and can enhance hands-on abilities (Slangen et al., 2011; Somyurek, 2015).

However, not all the reported results of using robotics are positive. LEGO robotics camps can enhance students' physics content knowledge, but have been found to have a non-significant effect on scientific inquiry skills (Williams et al., 2008). Moreover, Hussain et al. (2006) found negative attitudes toward the LEGO robotics curriculum, and a non-significant impact on problem-solving skills. Above all, most studies lacked discussion of mathematics and integrated STEM concepts (Alimisis, 2013; Nugent et al., 2016); these studies involved only small or isolated groups (Alimisis, 2013) with short interventions (Benitti, 2012). To have an encompassing view of the integrated robotics STEM curriculum (Benitti, 2012; Rihtaršič et al., 2016; Slangen et al., 2011), the effect of a regular curriculum should also be evaluated (Benitti, 2012; Eguchi, 2016). Therefore, this study explored the effects on students of a semester-long integrated robotics STEM course; the results were compared to those of learning in a LEGO $^{\circledR}$ robotics-based curriculum.

\section{THE EXPERIMENTAL INTEGRATED ROBOTICS STEM COURSE IN THE CURRENT STUDY}

\section{Comparison of Commercial and Homemade Robot Kits}

A few companies, such as LEGO ${ }^{\circledR}$ and Fischertechnik, provide robot kits with illustrations of tasks, like obstacle avoidance, tracing, weighting, and shooting, using wheeled robots (Jojoa et al., 2010; Somyürek, 2015; Yuen et al., 2014) or walking robots (Jojoa et al., 2010; Pa \& Wu, 2012). Benitti (2012) found that $90 \%$ of studies adopted LEGO ${ }^{\circledR}$ robot kits, and that they had a positive impact on education. Nevertheless, Park and Kim (2011) pointed out that one of the goals of robotics education is to let students choose materials and apply what they have learned in class to create their own robots. For example, to build a fish robot, students have to apply scientific knowledge to understand the functions of fish fins and the ways of moving, and to investigate the optimal shape for movement. These processes are omitted when building commercial robots. The homemade fish robot project can successfully inspire students' interest in the field of STEM (Abaid et al., 2013).

Besides, the advances in open source hardware and software have reduced the barriers to making homemade robots. For example, Arduino is an open source single-chip controller using script languages such as Java or C, or graphical/visual programming environments such as Scratch and Ardublock (Fernandes, Couceiro, Portugal, Machado Santos, \& Rocha, 2015; López-Rodríguez \& Cuesta, 2016). It is small, cheap, and easy to learn. Learners can quickly get started and engage in robotics experiments with Arduino (Araújo et al., 2015; Arduino, 2015). There are courses in college or high school adapting open hardware or software. For example, Galeriu, Edwards, and Esper (2014) used Arduino to collect data in experiments of motion, and Peppler (2013) created a STEAM course using Arduino. 
Table 1. A comparison of $\mathrm{LEGO}^{\oplus}$ Mindstorms and Arduino robot kits

\begin{tabular}{llll}
\hline & LEGO ${ }^{\circledR}$ Mindstorms EV3 & Arduino UNO & Reference \\
\hline Cost & high & low & $\begin{array}{l}\text { López-Rodríguez \& Cuesta, 2016; } \\
\text { Mondada et al, 2017 }\end{array}$ \\
\hline Controller Weight (g) & $>240$ & 25 & Arduino, 2017 \\
\hline Controller Size (capacity) $\left(\right.$ inch $\left.^{3}\right)$ & $4.7 \times 3 \times 1.9$ & $2.7 \times 2.1$ & Araújo et al., 2015 \\
\hline Power (volts) & 9 & $7-12$ & Arduino, 2017 \\
\hline User age level (years old) & $>10$ & $>12$ & Arduino, 2017 \\
\hline Programming and interface & Graphical based & Text or Graphical based Sullivan \& Moriarty, 2009 \\
\hline Open and easy to get & + & +++ & López-Rodríguez \& Cuesta, 2016 \\
\hline Easy to use (Simple and easy assembly) +++ & + & Sullivan \& Moriarty, 2009 \\
\hline Save assembly time & + & +++ & Bers et al., 2014; \\
& & & Gonzalez-Gomez et al., 2012; \\
\hline Easy to restore & + & +++ & \\
\hline Compatible with other materials & ++ & +++ & \\
\hline Note: +++ great potential; ++ : potential with some limitations; $+:$ less friendly &
\end{tabular}

Moreover, commercial products with accessories have their pros and cons. It often takes much time for teachers to organize the components (Altin \& Pedaste, 2013; Bers et al., 2014; Gonzalez-Gomez, Valero-Gomez, PrietoMoreno, \& Abderrahim, 2012; Sullivan \& Heffernan, 2016) and for students to familiarize themselves with them. In addition, they are inadequate for supporting students' creativity; it is hard for students to create their own designs while using commercial products. Students spend more time on assembly using the available parts in a robot kit rather than learning in-depth knowledge (Bers et al., 2014; Gonzalez-Gomez et al., 2012; Sullivan \& Moriarty, 2009), thinking, or creating. Table 1 summarizes the advantages and disadvantages of commercial and homemade robot kits using LEGO $^{\circledR}$ and Arduino as examples.

Table 1 shows that Arduino UNO has several advantages. First, with its light weight and small size, users can easily build water and sky transport as well as land vehicles. Secondly, the key factor for students and teachers to apply Arduino inside and outside school is its low cost. Finally, its flexibility and compatibility enables users to design and create freely by themselves. As the open system is affordable and could have follow-up expansions (Fortunati, Esposito, Ferrin, \& Viel, 2014), students can design their own robots using a wide variety of materials, such as balsa wood, foam board, cardboard, steel wire, wooden sticks, and so on. Therefore, the experimental course in this study used Arduino UNO.

\section{The Integrated Robotics STEM Course in the Current Study}

The aim of the current robotics course was to integrate knowledge in all STEM fields. Fogarty, Stoehr, and Gardner (2008) summarized several approaches for developing an integrated curriculum. The present course adopted the web approach, in which the concepts in different disciplines and the anticipated learning objectives were integrated into a theme. The theme chosen for this course was sailboats (Figure 1), because it required concepts of physics (motion and force), mathematics (trigonometric and function), and engineering design (illustration and optimization) (Figure 2). Additionally, we developed a low-cost and resilient version of a sailboat robot. We adopted the Arduino UNO controller, electronic circuits, and free design materials to construct the sailboat robot, with the entire system costing less than US\$30. 


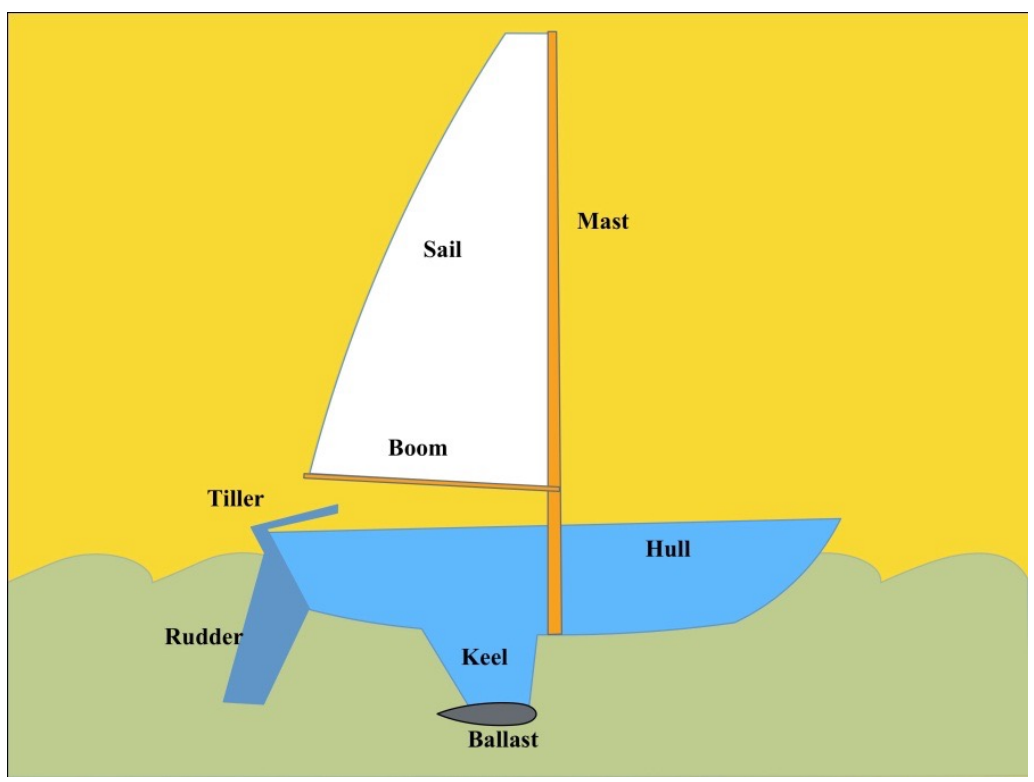

Figure 1. Sailboat construction draft and parts

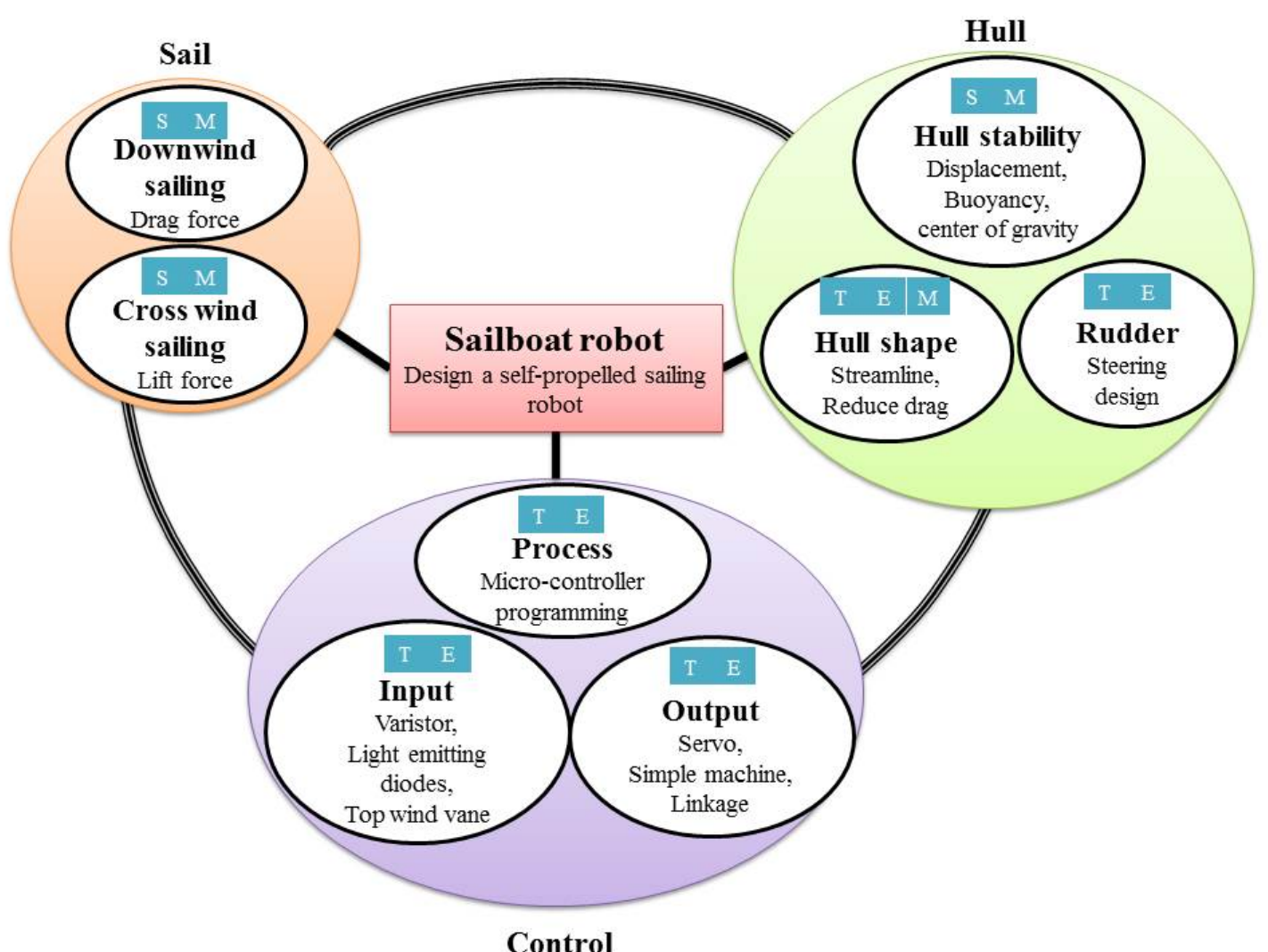

Figure 2. Web model of the STEM-integrated course on engineering a sailboat robot Note: S: Science, T: technology, E: engineering, M: mathematics

We referenced Jaulin and Le Bars's (2013) design of an automatic sailboat, which combines stability, force, and automatic control. We then analyzed the STEM knowledge applicable to each section of the sailboat, as shown in Figure 2.

1. Sail: The design of the sail involves scientific and mathematics knowledge. Downwind sailing is mainly driven by drag force, whereas sailing across wind relies on lift force. Students learned physic concepts about lift and drag forces and calculated the angles between the sail and wind direction (Figure 3). Furthermore, 


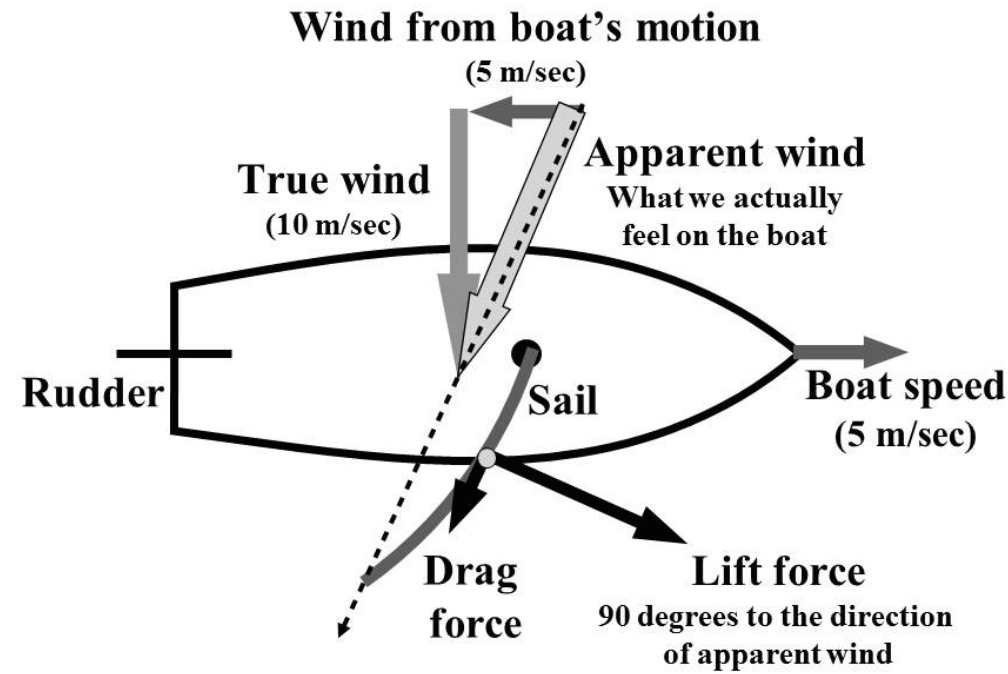

Figure 3. Force diagram of true wind and apparent wind on sailing

students cut shapes of sails from foam board or cardboard and carried out experiments to optimize the shapes and sizes of the sails.

2. Hull: The design of the hull utilizes scientific knowledge, including displacement, buoyancy, center of gravity and stability, the hull's drag force, and mathematic concepts, including the calculation of the surface area and volume of the hull. Students designed and tested the shape of the hull and the rudder using foam boards, and the stability of the hull in the water. All of these are important for sailboat engineering design. Likewise, students had to carry out experiments to optimize the shape and displacement of the hull.

3. Control: The control system is indispensable for an auto-sailing robot. Prior knowledge is required of not only the Arduino UNO controller and Arduino Software (IDE) programming, but also of the electronic parts such as jumper wires, LEDs, variable resistance, photoresistors, servos, as well as their assemblage. The algorithm is that the rotation of the weather vane changes the variable resistance, which inputs signals to the Arduino UNO controller. Then, the controller, based on the programming, outputs an electrical voltage to the servo, which adjusts the sail and rudder. Students used sensors such as photo-resistors to manipulate the direction of the sailboats.

This study adopted the task-centered teaching model proposed by Merrill (2002, 2007, 2009). The task-centered instructional strategy stresses the introduction of a final task at the beginning of the course. The task should be authentic and divisible into several sub-tasks, which require different concepts and skills. In each class period, a limited number of new concepts or topics were taught and a sub-task was carried out. Students completed the final task at the end of the course. The final task of the current integrated STEM course is to design a sailboat robot capable of sailing freely. The objective was decomposed into eight units (Figure 4), each consist of a subtask as shown in Figure 5: 1. make a sail car; 2. make a hull; 3.program and apply Arduino using a breadboard to control the electronic components (e.g., LED, motor, etc.); 4. program with Arduino to actuate the linkage and rudder by the sensor input signals; 5 . assemble the sail and the Arduino UNO controller into the hull; 6. program for auto sailing control; 7. adjust and tune the sailboat robotics; 8 . complete the self-sailing sailboat robotics). 


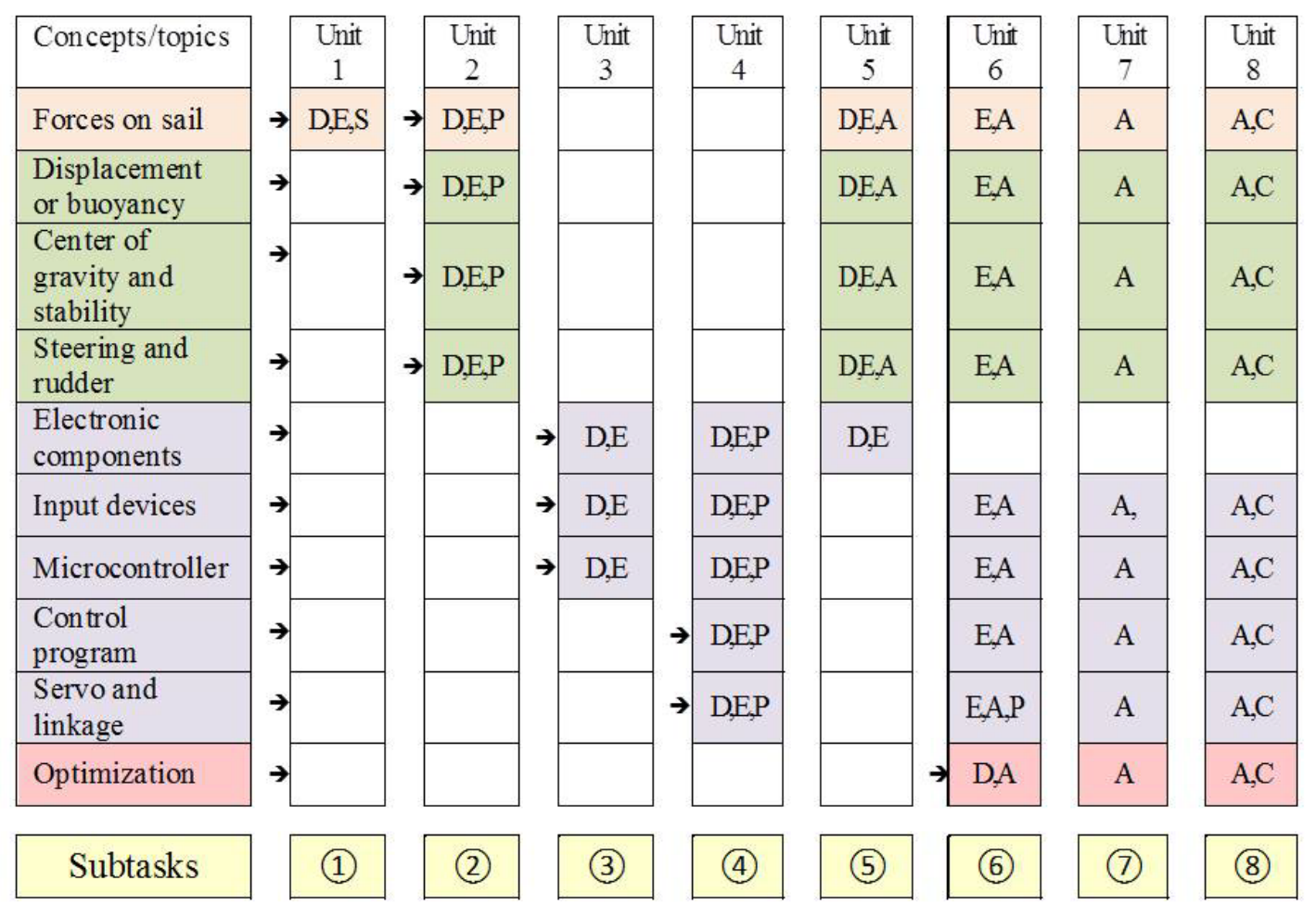

Figure 4. Instruction procedure task-oriented integrated course for engineering a self-propelled sailing robot Note : $\rightarrow$ teacher introduces new concepts/topics, D: teacher teaches and demonstrates, S: simulated experiment, E: physical experiment, A: hands-on and adjustment, P: prototype, C: competition

The concepts and topics (e.g., forces on the sail, displacement, or electronic components) of each unit are listed in Figure 4. After completing the eight subtasks (Figure 5), students should have been able to build a sailboat for a sailing race.

In Unit 1, the instructor introduced the forces on the sail and the relationship between forces and the surface area of the sail. Students conducted simulations by using the free application "Sail for Gold Game" to understand how to manipulate the movement of a sailboat. The sub-task for this unit is that students design and make a sail to drive a cart as fast as possible.

For Unit 2, the teacher instructed the geometry and buoyancy. Students designed and made a hull that could hold the Arduino UNO and necessary electronic parts without leaking; the hull was tested to race as fast as possible with the sail made in Unit 1.

In Unit 3, the instructor introduced Arduino UNO, the Arduino IDE programming language, and electronic components. Students learned to link Arduino and a breadboard to different electronic parts and programming to turn on and off the LEDs or servos with various sensors, such as photo-resistors, push buttons, and rotation sensors. They then verified and uploaded the programming code on Arduino to control the electronic circuits.

After Unit 3, in Unit 4 the students plugged input and output circuits into the breadboard, and electronic and programming concepts were incorporated into practice. The teacher described the servo and rudder design concepts, and showed an example of a mechanical linkage between the tiller and the boom. Students built a similar mechanical linkage, coded and debugged the program to control the servo with sensors. The task for this unit is to have the Arduino Uno automatically adjust the servo rotation angles and drive the linkage correctly, according to the input signals.

Unit 5 was for the students to assemble the sail and the hull created in Units 1 and 2, then load the autopilot system from Unit 4 in the hull. Students launched the home-made sailboat prototypes, and fixed leaks. 

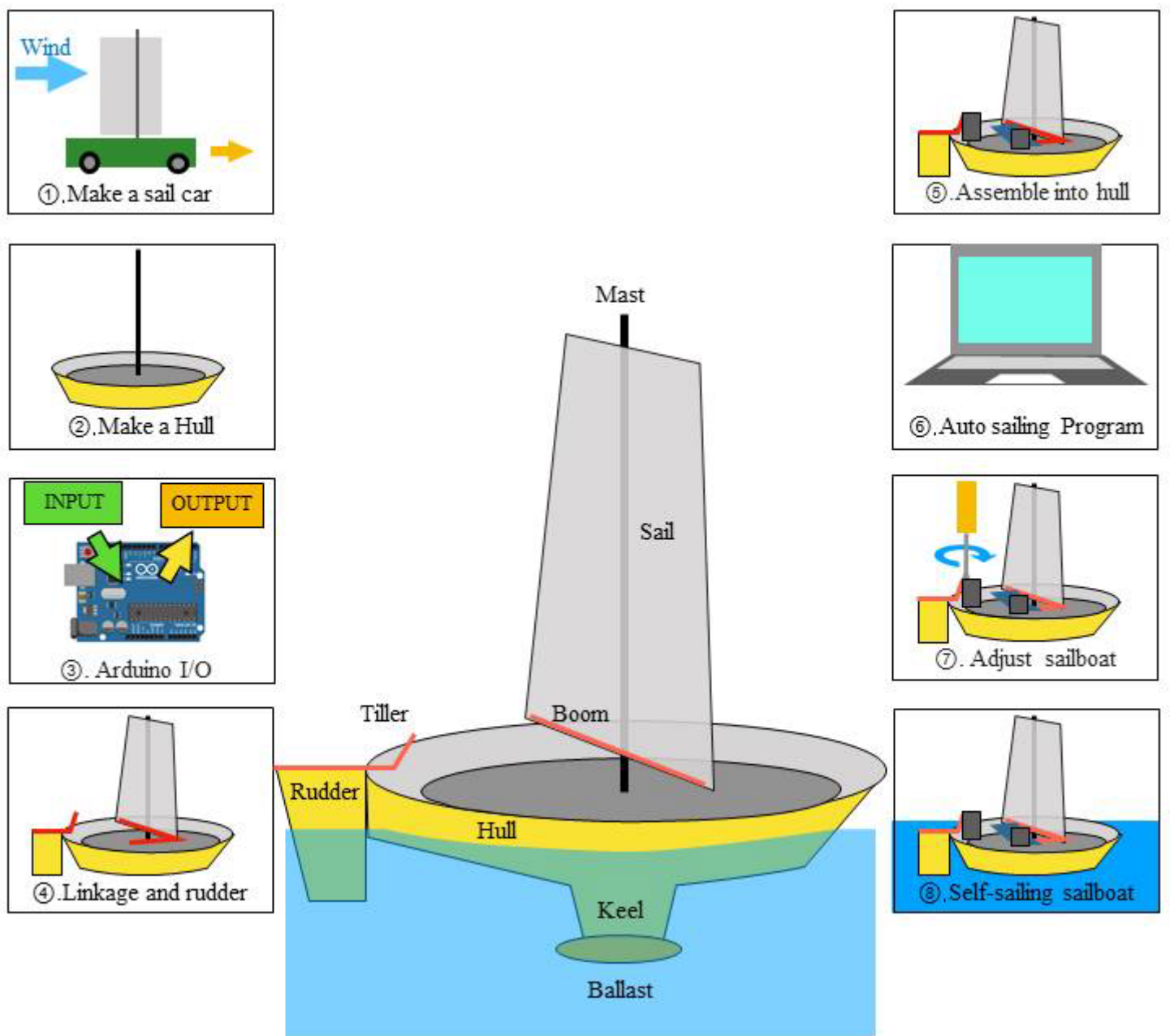

Figure 5. The eight subtasks of the self-propelled sailboat robot for the task-oriented integrated course

In Units 6 and 7, the teacher introduced important concepts in engineering design. For example, multi-objective optimization is concerned with mathematical optimization problems involving more than one objective function to be optimized simultaneously. Optimal decisions were made between trade-offs, such as low cost, high performance or lightness and stability. Students applied science and mathematics knowledge and skills to adjust and test the sailboat. The task aimed to test and optimize if the sailboat could be moved forward automatically by the wind.

In Unit 7, through hands-on experiments, students followed the above engineering design steps and put their knowledge and abilities from the above six units into practice. They prepared and tested their sails, hulls, and autopilot system design, which were later redesigned, improved, and tested again until the students were satisfied with their design and ready to compete against other teams. These procedures were repeated as many times as possible to prepare for the competition.

As for the last unit, the challenge was to work as engineers to develop efficient sailboat robotics using wind power. A competition of automated sailboat robotics was held at the end of the course, with students divided into groups of two. The rule was to have the self-made sailboat navigate as far as possible in a sink of one meter of $1 \mathrm{x}$ 0.5 meter. The length of the hull should be less than $30 \mathrm{~cm}$ for automatic navigation (Figure 6). 


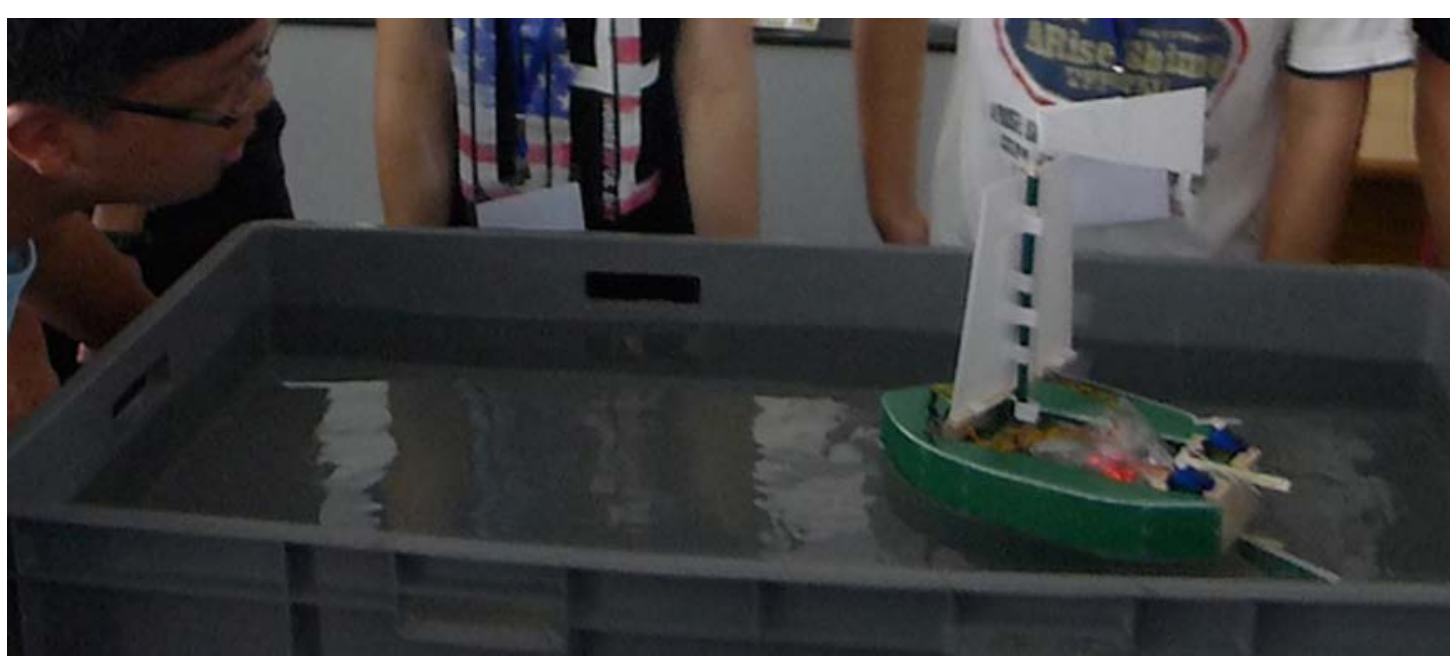

Figure 6. The self-propelled robotic sailboat

\section{RESEARCH METHOD}

\section{Research Design}

This study followed a quasi-experimental design, with two different curricula for the experimental (EG) and the control (CG) groups. Both groups were taught by the same teacher. Each curriculum lasted for 18 weeks with 2 hours per week. The EG learned with the integrated robotics STEM curriculum in a task-centered teaching model, including instruction of eight units/subtasks in sequence (Figure 4 and 5). The objectives were to learn integrated STEM concepts and make self-propelled sailboat robotics with an Arduino Uno controller and compatible electronic components.

The CG used a $\mathrm{LEGO}^{\circledR}$ robot kit with the $\mathrm{LEGO}^{\circledR}$ Mindstorms EV3 educational software tutorial program, in which they constructed basic cars, bumper cars, maze cars, line tracers with one light sensor, ball shoot cars, line tracers with two light sensors, and dancing robots. This intervention mainly focused on building and programming EV3 robots. STEM knowledge was not explicitly instructed.

To measure the two groups' initial perceptions of and career interest in STEM, two surveys were administered prior to the interventions. Post-surveys on STEM perceptions, career interest, and satisfaction with the curriculum were conducted after the robotics curriculum. The EG students took an extra test on integrated STEM knowledge before and after the intervention to evaluate their improvements. They also wrote weekly journals of their experiments and designs. As the CG's curriculum did not integrate STEM, they were not asked to take the integrated STEM knowledge test, which would make no sense to them.

\section{Participants}

The EG and CG consisted of 42 and 40 10th graders from the same high school. Students in the experimental group had already learned the concepts of ratio, volume, surface, arithmetic, and basic buoyancy, but not the calculation of buoyancy nor the concepts of lift force. There were 11 students in the control group and 13 in the experimental group who had taken extracurricular robotics courses.

\section{Research Instruments}

To evaluate the effectiveness of the curricula, four instruments were employed.

\section{Integrated STEM Perception Questionnaire}

Bybee (2010) found that most professionals in STEM-related fields lacked an understanding of the acronym STEM and its perceived values (importance and usefulness) from a recent survey on "perceptions of STEM." To successfully implement STEM education, we should understand the state of current perceptions and implementation. The Integrated STEM Perception Questionnaire was translated from Hernandez et al. (2014), including a total of eight items measuring students' perceptions of the integration of science, technology, engineering, and mathematics. They were administered with a 5-point Likert scale, from strongly disagree (1) to 
strongly agree (5) before and after the interventions. A sample question was as follows: "I will apply connections between science, technology, engineering and mathematics to help me solve problems in real life." Hernandez et al. (2014) documented the Cronbach's alpha coefficient of the scale as being .82. It was .83 in the current study.

\section{STEM Interest and Career Orientation Questionnaire}

This questionnaire was adapted from the Robotics Interest Scale (Yilmaz, Ozcelik, Yilmazer, \& Nekovei, 2013) and the Robotics STEM career orientation scale (Nugent et al., 2016). There were eight items in total for measuring continuous interest in a career in the STEM fields. The scale was validated by three experts. Items were on a 5-point scale ranging from strongly disagree (1) to strongly agree (5). This instrument was used as the pre- and post-tests. A Cronbach's alpha reliability coefficient of .95 was found according to the pretest. A sample question was: "I will study the engineering domain in university or college."

\section{Curriculum Satisfaction Questionnaire}

The aim of the questionnaire was to understand participants' satisfaction with the curriculum on a 5-point Likert-scale, adapted from Avsec et al. (2014). As Avsec et al. (2014) suggested, three factors (15 items in total) were evaluated, namely curriculum content, teacher's teaching, and organization and service. It was administered to both groups at the end of the courses.

The Cronbach's alpha reliability values of the scale were between .77 and .96 , indicating that the gauge had sufficient reliability. A sample item is: "I am willing to continue to participate in similar courses."

To probe students' opinions on curriculum satisfaction more widely and deeply, students of both groups were asked to address their gains from the courses and comments on the courses with two open-ended questions, "Please describe your experience participating in the course. Do you feel that the course was effective for developing your STEM learning?" and "Do you have any suggestions or perceptions of the course?"

\section{Integrated STEM Knowledge Test}

The integrated STEM Knowledge Test aimed to evaluate the learning achievements of the EG. It was tasksensitive, and thus not applicable to the CG. It covered concepts in science (drag force, lift force, displacement, and voltage in series/parallel), electronics (Arduino Uno, a breadboard, and input/ output electronic parts), technology and engineering (linkage, sensors, sail and hull design), computer programming (variable declaration, looping, and condition statements), mathematics (fractions, surface, volume, and trigonometry), and interdisciplinary knowledge (whole sailboat robotics design and problem solving). Two professors from Engineering/Robotics and three high school physics/technology teachers reviewed and helped to validate the content of the assessment. The same instrument was used as the pre- and post-tests. There were 10 multiple-choice and 40 fill-in-the-blank questions. Some questions were presented as a set. Each question was worth 2 points; the full score was 100 points.

Concerning the validity and reliability of the test, the discriminated test, correlation between item and total, and Kuder-Richardson Reliability 20 (KR20) were examined. Based on the pretest, the students were divided into high and low performers with the percentiles of $27 \%$ and $73 \%$. The $t$-test results of each item were significant $(p<0.05)$, indicating that all items were able to discriminate the performance. Moreover, the Pearson correlation coefficient among each item and the total score was between 0.527 and 0.875 , and all of them were significant $(p<0.05)$, indicating that there was an internal consistency between all items. Finally, the KR20 reliability coefficient was .71, showing a sufficient degree of internal consistency. The sample items are provided in the Appendix.

\section{DATA ANALYSIS}

Research Question 1 examined the effectiveness of the integrated STEM curriculum on students' perceptions of STEM integration. Two-tailed paired $t$ tests were used to compare the means of the pre- and post-tests of the Integrated STEM Perception Questionnaire in both groups. An analysis of covariance (ANCOVA) was conducted to determine if there was a difference between the two groups with the pretest as the covariate. To answer Research Question 2, the pre- and post-test of the STEM Interest and Career Orientation Questionnaire were also analyzed similarly.

Concerning Research Question 3, since the Curriculum Satisfaction Questionnaire was only given after two different interventions, $t$ tests were adopted to evaluate the two groups' satisfaction with the content, teaching, and organization. Moreover, a thematic analysis was conducted of the composite transcript of students' responses to the open-ended questions. We used the NVivo 9 software to facilitate the multi-level coding approach, using a word frequency query to generate lists of the most frequent words in a tree map or nodes (King, 2010). The data were coded in the top three nodes that represented student relatedness in synchronous hybrid programs: STEM 
Table 2. The effects of the integrated STEM course on students' perceptions

\begin{tabular}{llccccc}
\hline Group & $\begin{array}{c}\text { Pre-test } \\
\boldsymbol{M}(\boldsymbol{S D})\end{array}$ & $\begin{array}{c}\text { Posttest } \\
\boldsymbol{M}(\boldsymbol{S} \boldsymbol{D})\end{array}$ & $\begin{array}{c}\text { 2-tailed } \\
\boldsymbol{t} \text {-test }\end{array}$ & $\begin{array}{c}\text { Effect size } \\
\text { Cohen's } \boldsymbol{d}\end{array}$ & $\begin{array}{c}\text { ANCOVA } \\
\boldsymbol{F}(\mathbf{1}, \mathbf{8 0})\end{array}$ & $\begin{array}{c}\text { Effect size } \\
\boldsymbol{\eta}^{\mathbf{2}}\end{array}$ \\
\hline $\mathrm{EG}(n=42)$ & $2.52(0.25)$ & $3.45(0.51)$ & $13.39^{\star \star *}$ & 3.29 & $22.47^{\star \star *}$ & 0.25 \\
\hline $\mathrm{CG}(n=40)$ & $2.60(0.25)$ & $3.11(0.31)$ & $10.23^{\star \star *}$ & 1.62 & & \\
\hline${ }^{* \star} p<.001$ & & & & & &
\end{tabular}

Table 3. The effects of the integrated STEM curriculum on students' interest and career orientation

\begin{tabular}{|c|c|c|c|c|c|c|}
\hline Group & $\begin{array}{l}\text { Pre-test } \\
M(S D)\end{array}$ & $\begin{array}{l}\text { Posttest } \\
M(S D)\end{array}$ & $\begin{array}{c}\text { 2-tailed } \\
\text { t-test }\end{array}$ & $\begin{array}{c}\text { Effect size Cohen's } \\
d\end{array}$ & $\begin{array}{c}\text { ANCOVA } \\
F(1,80)\end{array}$ & $\begin{array}{c}\text { Effect size } \\
\eta^{2} \\
\end{array}$ \\
\hline$E G(n=42)$ & $2.96(0.25)$ & $3.63(0.34)$ & $13.18^{* * *}$ & 2.55 & $11.64^{\star \star}$ & 0.15 \\
\hline CG $(n=40)$ & $2.61(0.23)$ & $2.88(0.54)$ & $3.61^{* \star}$ & 0.67 & & \\
\hline
\end{tabular}

${ }^{\star *} p<.01,{ }^{* \star *} p<.001$

Table 4. Students' curriculum satisfaction

\begin{tabular}{|c|c|c|c|c|}
\hline Factor & $\begin{array}{c}\mathrm{EG}(\mathrm{n}=42) \\
M(S D)\end{array}$ & $\begin{array}{c}C G(n=40) \\
M(S D)\end{array}$ & $\begin{array}{c}\text { 2-tailed } \\
t \text { test }\end{array}$ & $\begin{array}{l}\text { Effect size } \\
\text { Cohen's d }\end{array}$ \\
\hline Curriculum content & $4.43(0.49)$ & $3.78(1.05)$ & $2.97^{\star \star}$ & 2.08 \\
\hline Teacher's teaching & $4.63(0.44)$ & $3.65(1.06)$ & $4.51^{\star \star \star *}$ & 3.16 \\
\hline Organization and service & $4.42(0.59)$ & $3.78(0.95)$ & $3.08^{\star \star}$ & 2.16 \\
\hline Total & $4.43(0.45)$ & $3.78(0.93)$ & $3.32^{\star \star}$ & 2.33 \\
\hline
\end{tabular}

knowledge and skills, belief/ motivation, and Robot material. The results section provides evidence of the emergent perceptions that supported the identification and development of each of the key themes.

To answer the fourth question, paired $t$ tests were carried out to examine whether the curriculum had significant effects on the EG students' learning achievements concerning concepts of sailboat design, science, mathematics, mechanics, electronics, and robotics. Two observers independently coded all groups' scores from this competition. To test for inter-rater reliability, the coding of all responses was analyzed with Cohen's (1960) kappa $(k=.80)$.

\section{RESULTS}

\section{The Effects of the Curricula on Students' Perceptions of the STEM Integration}

The paired $t$ tests showed significant increases in perception for both EG and CG students from the pre- to posttests, $t=13.39,10.23 ; p<.001$ (Table 2). Moreover, the ANCOVA revealed that the EG students had significantly more positive perceptions of STEM integration, compared to the CG students, $F(1,80)=22.47$; $\mathrm{p}<.001$. The effect size was large. In other words, the integrated robotics STEM curriculum could further boost students' perceptions to a higher level. This supported the effectiveness of the EG course.

\section{The Effects of the Integrated STEM Course on Students' Interest and Career Orientation}

The paired $t$ tests showed significant increases in interest and career orientation for the EG and CG students from the pre- to post-tests, $t=13.18,3.61, p<.01$, respectively (Table 3). Moreover, the ANCOVA revealed that the EG students had significantly different interests and career orientations towards STEM, compared to the CG students, with $F(1,80)=11.64$ and $p<.01$. In other words, the integrated robotics STEM curriculum further boosted the students' interest and career orientation to a higher level.

\section{Satisfaction with the Curriculum}

The EG had a high level of satisfaction with the overall curriculum, with $M(S D)=4.43(0.45)$ on a 5-point scale (Table 4). The EG was significantly higher than the CG in all sub-scales and overall satisfaction (Table 5). They were apparently more satisfied with the curriculum content $(t(80)=2.97, \mathrm{p}<.01)$, teacher's teaching $(t(80)=4.51$, $\mathrm{p}<.001)$, and organization and service $(t(80)=3.08, \mathrm{p}<.01)$. The effects were large (Cohen's $\mathrm{d}=2.08-3.16)$. 
Table 5. Integrated STEM knowledge experimental group pre/post-test scores

\begin{tabular}{|c|c|c|c|c|c|c|}
\hline \multirow{2}{*}{ Factor } & \multicolumn{2}{|c|}{ Pre-test } & \multicolumn{2}{|c|}{ Post-test } & \multirow{2}{*}{$t(41)$} & \multirow{2}{*}{$\begin{array}{l}\text { Effect size } \\
\text { Cohen's d }\end{array}$} \\
\hline & $M$ & $S D$ & $M$ & $S D$ & & \\
\hline Sailboat design & 4.83 & 1.965 & 11.66 & 3.706 & $11.23^{\star * *}$ & 3.476 \\
\hline Science & 11.93 & 3.484 & 20.14 & 4.955 & $10.39 * * *$ & 2.356 \\
\hline Mathematics & 8.28 & 1.907 & 10.76 & 1.806 & $6.77^{\star \star *}$ & 1.300 \\
\hline Mechanics & 2.69 & 0.967 & 5.10 & 1.372 & $9.63^{* \star \star}$ & 2.492 \\
\hline Electronics & 2.90 & 1.566 & 7.24 & 1.354 & $11.67^{\text {*** }}$ & 2.771 \\
\hline Programming & 5.52 & 2.115 & 10.62 & 2.007 & $12.26^{\star \star *}$ & 2.411 \\
\hline Robotics & 6.28 & 3.283 & 13.31 & 5.714 & $7.94^{\star * *}$ & 2.141 \\
\hline Total & 41.00 & 14.256 & 76.20 & 23.326 & $12.10^{\star \star \star}$ & 2.469 \\
\hline
\end{tabular}

Furthermore, both groups responded freely to two open-ended questions about their experiences of the curricula. Students' responses were coded into three categories: STEM knowledge and skills obtained, belief and motivation, and robotics material.

\section{STEM knowledge and skills obtained}

Many of the EG students mentioned that the course provided them with a better understanding of the concepts that were previously taught in the other courses such as physics and coding. The integrated STEM course linked abstract science concepts to practical work. Specifically, 11 EG students stated that they learned new science concepts from the course. For example, EG27: "This course allowed me to learn buoyancy, lift, and resistance concepts." And EG11: "I learned a lot about lift and drag force from the sailboat." EG6: "I could apply physics knowledge to the design of sailboats and airplanes."

Regarding linkage, many students $(n=12)$ pointed out that they could use steel wire to build a linkage between the rudder and the sail. For example, EG11: "I could use wire linkage between the angle of the sail and the rotation of the rudder." EG25: "Although the linkage design was more difficult, I succeeded finally."

Moreover, the EG students pointed out that they learned concepts of engineering design, and how to control and adjust variables of sailboat robot design. Group 11:

"I found that only one side of the photosensitive sensor reacted, so I checked the code first, and found that the code was right. Then, I replaced the photosensitive sensor, and the boat could sail"and EG30: "I learned to communicate with other students and know how to simplify the problem (change the variables one at a time)." EG27: "I can draw a design draft and cut the foam board to construct a sailboat."

It was very common that EG students' weekly journals mentioned how they solved problems: Group10: "To avoid light sensor resistance interfering with other light, I tried to design a cover plate
to avoid interference."

Group12: "In order to avoid the sailboat inclining, I increased the height of the hull."

Group11: "I found that the sails and rudders could not turn smoothly, so I tried to change the length of the wire and the center of the rudder piece and found that it improved. I also found that because the connecting rod was too short, it caused the motor not to drive the rudder; increase the length and it can be successfully driven.

I could not let the weather vane successfully drive the rotary potentiometer, with sail and rudder linkage means are not successfully driven, so I needed to learn to effectively make a complete plan within a limited period of time to complete the work and learn to master my time."

Group18: "We made three different sailboats and tried out which one would be better."

On the contrary, none of the CG students mentioned the learning of science, engineering, or problem solving.

In terms of programming design, the students responded that they learned to program after the two curricula. For example, $10 \mathrm{EG}$ students mentioned that they learned to program text scripts. At the same time, three CG students mentioned that they wanted to learn script programming, for example CG22: "I want to learn another programming language such as C or JAVA, not just LEGO programming."

The sailboat course could foster students' understandings of concepts in science, engineering design, programming, and problem solving. It could also enhance their intentions and motivation to learn STEM. 


\section{Intention/motivation}

Most EG students mentioned that the sailboat-themed course was interesting and that they were willing to continue learning similar programs. For example, EG3: "Our sailboat can be controlled by Arduino. Arduino is not difficult!"; EG27: "I felt a strong sense of accomplishment."; EG12: "I hope that the school can offer this course again." At the same time, seven CG students mentioned that they wished to learn about robotics; for example, CG32: "I am very curious to make a robot of my own and am willing to make another robot."

It could be inferred from these comments that the two curricula had an impact on the students' beliefs and motivation. Both groups demonstrated changes in their beliefs and motivation. Before they might have felt that it was difficult to make robots, but now they expressed an increase in interest and career orientation, as shown in the pre- and post-surveys. This finding was consistent with Abaid et al. (2013) and Cristoforis et al. (2013).

\section{Material/equipment}

The CG students had more comments on this category. For example, eight CG students commented that LEGO ${ }^{\circledR}$ was too expensive. They did not have LEGO $^{\circledR}$ at home. On the one hand, they felt grateful to have such expensive materials. On the other hand, their learning was discontinued after school. Therefore, some of them suggested using home materials. For example:

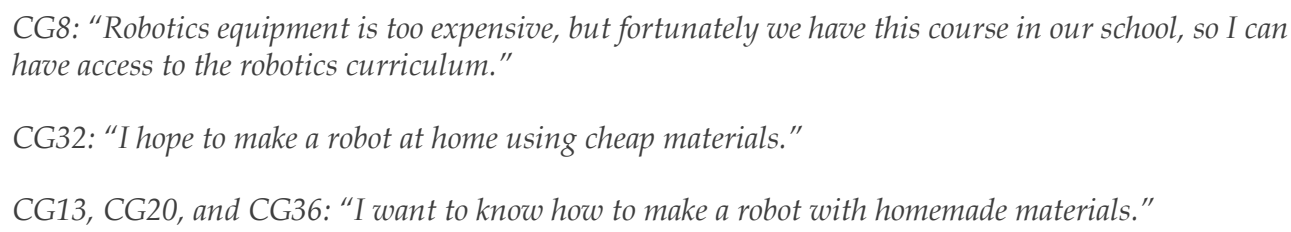

The results suggest that the CG students would prefer homemade material learning, even if their experiences with $\mathrm{LEGO}^{\circledR}$ were good. By contrast, the EG students could make sailboats at home. The extensive learning after school was crucial to their learning and thinking.

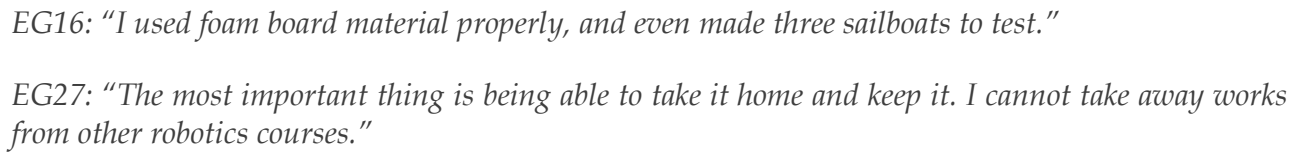

Furthermore, $\mathrm{LEGO}^{\circledR}$ was inflexible to some extent. For example, CG7 said: "LEGO ${ }^{\circledR}$ is like a toy. I can't make many changes since all the parts are modular E plug and play." CG23 said: "I hope that the teacher can teach us more about the electronic parts and knowledge of robotics."

Due to the same reason, the CG students had limited gains in their electronic and science knowledge. To sum up, using Arduino and open source robot kits for our purposes had more benefits than drawbacks, and it fitted well with the development of the practical exercises we had designed.

\section{The Effect of the Integrated STEM Curriculum on Students' Knowledge}

A task-sensitive test was given to the EG students, who had improved significantly in the seven dimensions, namely the sailing design, science, mathematics, machinery, electronic components, computer programs and robotics, as shown in Table 5. The effects of all seven dimensions were large (Cohen's $d=1.30-3.48)$. While most of the previous studies only explored the increase in two to three dimensions, this study found that the integrated STEM curriculum promoted learning in all seven dimensions.

In the final mission, the students achieved a goal rate of $85.7 \%(18 / 21)$; that is, 18 out of the 21 sailing robots arrived at the end point within 3 minutes. The best sailboat took 4.4 seconds sailing 1 meter, followed by three in 5.6 seconds. These performances showed that the students had gained adequate robotics skills and the curriculum was appropriate. In line with Park and Kim (2011), students used low-cost and open source robotics artifacts, with hand tools and limited materials (such as balsa wood and color foam board), which could stimulate their interest and their hands-on and illustration abilities. 


\section{DISCUSSION AND CONCLUSIONS}

\section{Research Claim 1: The Integrated STEM Curriculum Significantly Improved Students' Perceptions of the Importance and Integration of STEM}

The EG learned with the integrated sailboat robotics STEM course, whereas the CG learned with the LEGO ${ }^{\circledR}$ curriculum. Both groups improved their perceptions of the importance of the science, technology, engineering, and mathematics subjects and the integration of these subjects in solving problems from the pre- to post-tests. Moreover, the EG had higher effect size, and the post-test score was significantly higher than that of the CG. According to Binns, Polly, Conrad, and Algozzine (2016), Nugent et al. (2010) and Nugent et al. (2016), LEGO ${ }^{\circledR}$ robotics programs could enhance students' positive attitudes toward the importance and integration of STEM subjects. Our study further found that the integrated sailboat robotics STEM course could boost students' perceptions to a higher level. This result demonstrated that a curriculum where STEM was well integrated had its unique value for STEM education.

\section{Research Claim 2: The Effect of the Integrated STEM Curriculum on Students' STEM Interest and Career Orientation was Effective}

Similar to Claim 1, in both groups, interest and career orientation toward STEM were raised. According to Yilmaz et al. (2013), when students actively engage with engineering practices, they develop a higher interest in engineering. Our study found that both robotics courses had a positive effect on students' STEM interest and career orientation. The engineering practices via operating the $\mathrm{LEGO}^{\circledR}$ and Arduino robots seemed to engage the students and enhance their interest.

Furthermore, the results validated the claim by Doerschuk et al. (2016) that hands-on robotics can enhance students' interest and career advancement in STEM. The results also verified Eguchi's (2016) claim that robotics can provide students with practices, thematic production, and goal-oriented learning experience, and can have a longterm impact on students' future learning in STEM fields (Eguchi, 2016).

Moreover, the EG students reported significantly higher interest and career intentions toward STEM than did the CG students after the programs. This finding extends the research focusing on LEGO ${ }^{\circledR}$ (Nugent et al., 2016; Ucgul \& Cagiltay, 2014; Williams et al., 2008; Yuen et al., 2014) and suggests that the integrated STEM course on sailboat robotics was more effective in terms of enhancing students' interest.

Along with Claim 1, we concluded that the integrated STEM curriculum on sailboat robotics increased the students' perceptions of and interest in STEM, which are crucial for engaging students in the STEM fields. The literature has pointed out that to change students' interest in STEM or their future career tendencies, STEM-related activities and curricula need to be added in high school (Rockland, Bloom, Carpinelli, Burr-Alexander, Hirsch, \& Kimmel, 2010).To strengthen national competitiveness, there is a need to develop a large number of STEM talents (Langdon, McKittrick, Beede, Khan, \& Doms, 2011). Therefore, it is very important to enhance high school students' awareness of STEM's application in the social environment and the cultivation of future professional interest. This study found that after a semester of high school robotics courses, the students' attitudes towards STEM were significantly enhanced.

\section{Research Claim 3: Students were Satisfied with the Integrated STEM Curriculum}

Both the EG and CG had a high level of overall curriculum satisfaction. This indicates that the two courses' design and implementation were good to excellent. Because constructing a self-sailing robot is challenging, few researchers have used it in high schools. As mentioned in the results section, the students felt a sense of accomplishment due to these challenges. In particular, in the last competition, 42 students produced a total of 21 vessels, of which 14 were able to sail smoothly from the very beginning. Seven groups of students encountered difficulties when sailing, though in the end four groups solved their problem despite the time pressure; the other three groups did not finish the race.

The choice of cheap material also contributed to the students' satisfaction. Fortunati et al. (2014) already advocated the use of open software and hardware, as well as simple tools and materials to create robots. Mondada et al. (2017) also pointed out that price is the key in adopting robot kits in schools. This study used an open, easyto-handle controller and a foam board to replace expensive blocks. Therefore, the students had a chance to design their own robots. In addition, because the materials were cheap and easy to handle, students could take their sailboats home to resume work after school. 


\section{Research Claim 4: The Effect of the Integrated STEM Curriculum on Students' STEM Knowledge was Effective}

The study found that the integrated STEM curriculum on sailboat robotics had a positive impact on seven dimensions. While most previous literature only explored two to three dimensions in their curricula, our study integrated sailboat design, science, mathematics, mechanics, electronics, programming, and robotics; students' progress was significant in all dimensions. Specifically, electronics was included as Avsec et al. (2014) indicated that electronics is important in robotics education. Nevertheless, it is often built into commercial robotics packages and is invisible from the outside.

Through the process of making sailing robots, students learned the basics of drawing sailing designs, fluid mechanics, gravity and buoyancy principles, the use of electronic components, programming, and applications, thus achieving significant progress in integrating STEM knowledge. Compared to land-based running robots, the construction of a boat made it necessary to consider more scientific questions such as: Is there enough buoyancy to carry the heavy electronic equipment? Is the size of the sail appropriate? And can the direction of the sail be automatically adjusted to move forward? The sailboat is therefore a suitable theme to integrate STEM.

\section{IMPLICATIONS}

Robotics offers an engineering-based platform that combines STEM concepts as a way for students to solve problems collaboratively or to reach a common goal. This study is in line with Eguchi's (2016) finding that students are able to solve problems which arise in robot races and to complete tasks, analyze and dismantle a big problem into small problems, and think logically. The sailboat-themed course allows students to apply scientific knowledge and carry out systematic tests, rather than using trial and error to accomplish the mission.

Compared to $\mathrm{LEGO}^{\circledR}$, which is expensive and has shape and size restrictions, Arduino has advantages such as low price, small size and high extensibility. Using the Arduino controller, students can not only understand the concepts of electronic components and robotic parts but can also learn to design, manufacture and combine these robotic parts, such as the sails and hulls of sailing robots, with scientific and mathematical knowledge. In order to create a robotic sailboat, students must apply various kinds of knowledge to design the hull, sail, rudder, and the concept of automatic control is required to design an optimized autonomous navigation robot. Although the teacher introduces the basics of sailing design, students must draw their own sailboat drafts, cut materials and stick foam board to build, design and make a hull to hold the Arduino controller and electronic components that will not leak. Above all, students are allowed to use free cutting material to design the shape and area of the sail, the size of the cabin, the arc from the bow to the stern, etc.

The findings of this study provide suggestions for interested teachers from a broad background of teaching robotics and integrated STEM skills. The first suggestion is that the curriculum can adopt an integrated web approach, using a theme such as a sailboat to incorporate STEM knowledge.

The second suggestion is to adopt a task-oriented instructional strategy. The final task should be challenging and divisible into small tasks, so that students learn gradually and work toward the objectives. As Kubilinskiene, Zilinskiene, Dagiene, and Sinkevièius (2017) pointed out, with a strong correlation between tasks, students can accumulate a sense of achievement from each stage, for example, from the prototype of a boat, fitted with sails, coupled with an automatic driving controller and program control, calculating buoyancy, to self-sailing. The taskoriented teaching strategy stimulates students' STEM thinking, interest, and work tendencies around STEM. Therefore, the teaching strategy adopted in this study can serve as a reference for follow-up research. Thirdly, educators may use robotics material that is easy to acquire and inexpensive, such as open software and hardware.

Finally, the integrated sailboat robotics STEM course can be extended in several ways. This study applied a single sail and a single hull. Future studies can use two or more sails and hulls, combine GPS devices into the sailboat, enlarge the sailboat size, or apply an algorithm to navigate, depending on the learners' ability.

\section{STUDY LIMITATIONS AND FURTHER RESEARCH}

In this study, the integrated curriculum was confounded with the task-oriented teaching strategy. As such, it is difficult to identify the major cause of the positive effects. Future studies may investigate whether there are specific variations in teaching practices that are particularly salient to the learning and satisfaction of the experimental students. Moreover, the present study involved more male (about 2/3) than female students. Future studies may clarify whether the results can be explained by gender differences, and evaluate the long-term effects on female students' perceptions of STEM. 


\section{REFERENCES}

Abaid, N., Kopman, V., \& Porfiri, M. (2013). An attraction toward engineering careers: The story of a Brooklyn outreach program for KuFFFD12 Students. IEEE Robotics $\mathcal{E}$ Automation Magazine, 20(2), 31-39. https:/ / doi.org/10.1109/MRA.2012.2184672

Abdel-Salam, T., Sawaf, N. E., \& Williamson, K. (2009). Robotics explorations to enhance information technology literacy in rural schools. Journal of Communication and Computer, 6(3), 55-63. Retrieved from http:/ / www.airitilibrary.com/Publication/alDetailedMesh?DocID=15487709-200903-6-3-55-63-a

Alimisis, D. (2013). Educational robotics: Open questions and new challenges. Themes in Science E Technology Education, 6(1), 63-71. Retrieved from http://earthlab.uoi.gr/theste/index.php/theste/article/view/119

Altin, H., \& Pedaste, M. (2013). Learning approaches to applying robotics in science education. Journal of Baltic Science Education, 12(3), 365-377. Retrieved from https://journals.indexcopernicus.com/search/article? icid $=1054482$

Araújo, A., Portugal, D., Couceiro, M. S., \& Rocha, R. P. (2015). Integrating Arduino-based educational mobile robots in ROS. Journal of Intelligent E Robotic Systems, 77(2), 281-298. https:// doi.org/10.1007/s10846-013$0007-4$

Arduino. (2017). Retrieved on 20 March 2017 from https:/ / www.arduino.cc/

Avsec, S., Rihtaršič, D., \& Kocijancic, S. (2014). A predictive study of learner attitudes toward open learning in a robotics class. Journal of Science Education and Technology, 23(5), 692-704. https://doi.org/10.1007/s10956014-9496-6

Barak, M., \& Zadok, Y. (2007). Robotics projects and learning concepts in science, technology and problem solving. International Journal of Technology and Design Education, 19(3), 289-307. https:/ / doi.org/10.1007/s10798-0079043-3

Barker, B. S., \& Ansorge, J. (2007). Robotics as means to increase achievement scores in an informal learning environment. Journal of Research on Technology in Education, 39(3), 229-243. https:/ / doi.org/10.1080/15391523.2007.10782481

Becker, K., \& Park, K. (2011). Effects of integrative approaches among science, technology, engineering, and mathematics (STEM) subjects on students' learning: A preliminary meta-analysis. Journal of STEM Education: Innovations and Research, 12(5/6), 23. Retrieved from http://ojs.jstem.org/index.php?journal=JSTEM\& page $=$ article\&op $=$ view \&path[] $=1509$

Benitti, F. B. V. (2012). Exploring the educational potential of robotics in schools: A systematic review. Computers $\mathcal{E}$ Education, 58(3), 978-988. https:/ / doi.org/10.1016/j.compedu.2011.10.006

Bers, M. U., Flannery, L., Kazakoff, E. R., \& Sullivan, A. (2014). Computational thinking and tinkering: Exploration of an early childhood robotics curriculum. Computers $\mathcal{E}$ Education, 72(2014), 145-157. https:/ / doi.org/10.1016/j.compedu.2013.10.020

Binns, I. C., Polly, D., Conrad, J., \& Algozzine, B. (2016). Student perceptions of a summer ventures in science and mathematics camp experience. School Science and Mathematics, 116(8), 420-429. https://doi.org/10.1111/ssm.12196

Bybee, R. W. (2013). Case for STEM Education: Challenges and Opportunities. Arlington, VA, USA: National Science Teachers Association.

Cohen, J. (1960). A coefficient of agreement for nominal scales. Educational and Psychological Measurement, 20(1), 3746. https:/ / doi.org/10.1177/001316446002000104

Cristoforis, P. D., Pedre, S., Nitsche, M., Fischer, T., Pessacg, F., \& Pietro, C. D. (2013). A behavior-based approach for educational robotics activities. IEEE Transactions on Education, 56(1), 61-66. https://doi.org/10.1109/TE.2012.2220359

Doerschuk, P., Bahrim, C., Daniel, J., Kruger, J., Mann, J., \& Martin, C. (2016). Closing the gaps and filling the STEM pipeline: A multidisciplinary approach. Journal of Science Education and Technology, 1-14. https:/ / doi.org/10.1007/s10956-016-9622-8

Eguchi, A. (2016). RoboCupJunior for promoting STEM education, 21st century skills, and technological advancement through robotics competition. Robotics and Autonomous Systems, 75, 692-699. https:/ / doi.org/10.1016/j.robot.2015.05.013

English, L. D. (2016). STEM education K-12: Perspectives on integration. International Journal of STEM Education, 3(1), 1-8. https:/ / doi.org/10.1186/s40594-016-0036-1 
Fernandes, A., Couceiro, M. S., Portugal, D., Machado Santos, J., \& Rocha, R. P. (2015). Ad hoc communication in teams of mobile robots using zigbee technology. Computer Applications in Engineering Education, 23(5), 733745. https:/ / doi.org/10.1002/cae.21646

Fogarty, R., Stoehr, J., \& Gardner, H. (2008). Integrating curricula with multiple intelligences (2nd ed.). Thousand Oaks, CA: Corwin Press A sage Publication Company.

Fortunati, L., Esposito, A., Ferrin, G., \& Viel, M. (2014). Approaching social robots through playfulness and doingit-yourself: Children in action. Cognitive Computation, 6(4), 789-801. https://doi.org/10.1007/s12559-0149303-y

Galeriu, C., Edwards, S., \& Esper, G. (2014). An Arduino investigation of simple harmonic motion. The Physics Teacher, 52, 157-159. https://doi.org/10.1119/1.4865518

Gaudiello, I., \& Zibetti, E. (2013). Using control heuristics as a means to explore the educational potential of robotics kits. Themes in Science and Technology Education, 6(1), 15-28. Retrieved from http:/ / earthlab.uoi.gr/theste/index.php/theste/article/view/115/81

Gonzalez-Gomez, J., Valero-Gomez, A., Prieto-Moreno, A., \& Abderrahim, M. (2012). A new open source 3Dprintable mobile robotic platform for education. In U. Rückert, S. Joaquin, \& W. Felix (Eds.), Advances in autonomous mini robots (pp. 49-62). Berlin Heidelberg, Germany: Springer. https:// doi.org/10.1007/978-3642-27482-4_8

Hagedorn, L. S., \& Purnamasari, A. V. (2012). A realistic look at STEM and the role of community colleges. Community College Review, 40(2), 145-164. https:/ / doi.org/10.1177/0091552112443701

Hernandez, P., Bodin, R., Elliott, J., Ibrahim, B., Rambo-Hernandez, K., Chen, T., \& Miranda, M. (2014). Connecting the STEM dots: Measuring the effect of an integrated engineering design intervention. International Journal of Technology and Design Education, 24(1), 107-120. https:/ / doi.org/10.1007/s10798-013-9241-0

Hussain, S., Lindh, J., \& Shukur, G. (2006). The effect of Lego training on pupils' school performance in mathematics, problem solving ability and attitude: Swedish data. Educational Technology E Society, 9(3), 182194. Retrieved from http://www.ifets.info/journals/9_3/16.pdf

Jaulin, L., \& Le Bars, F. (2013). An interval approach for stability analysis: Application to sailboat robotics. IEEE Transactions on Robotics, 29(1), 282-287. https:// doi.org/10.1109/TRO.2012.2217794

Jojoa, E. M. J., Bravo, E. C., \& Cortes, E. B. B. (2010). Tool for experimenting with concepts of mobile robotics as applied to children's education. IEEE Transactions on Education, 53(1), 88-95. https://doi.org/10.1109/TE.2009.2024689

Kennedy, T. J., \& Odell, M. R. L. (2014). Engaging students in STEM education. Science Education International, 25(3), 246-258. Retrieved from http://www.icaseonline.net/sei/september2014/p1.pdf

King, A. (2010). 'Membership matters': Applying membership categorization analysis (MCA) to qualitative data using computer-assisted qualitative data analysis (CAQDAS) software. International Journal of Social Research Methodology, 13(1), 1-16. https:/ / doi.org/10.1080/13645570802576575

Kubilinskiene, S., Zilinskiene, I., Dagiene, V., \& Sinkevièius, V. (2017). Applying Robotics in School Education: a Systematic Review. Baltic Journal of Modern Computing, 5(1), 50-69. https://doi.org/10.22364/bjmc.2017.5.1.04

Langdon, D., McKittrick, G., Beede, D., Khan, B., \& Doms, M. (2011). STEM: Good Jobs Now and for the Future. ESA Issue Brief\# 03-11. US Department of Commerce.

Lindh, J., \& Holgersson, T. (2007). Does lego training stimulate pupils' ability to solve logical problems? Computers $\mathcal{E}$ Education, 49(4), 1097-1111. https:/ / doi.org/10.22364/bjmc.2017.5.1.04

López-Rodríguez, F. M., \& Cuesta, F. (2016). Andruino-A1: Low-cost educational mobile robot based on Android and Arduino. Journal of Intelligent \& Robotic Systems, 81(1), 63-76. https:/ / doi.org/10.1007/s10846-015-0227$x$

Merrill, M. D. (2002). First principles of instruction. Educational Technology Research \& Development, 50(3), 43-59. https:/ / doi.org/10.1007/BF02505024

Merrill, M. D. (2009). Finding e ${ }^{3}$ (effective, efficient, and engaging) Instruction. Educational Technology, 49(3), 15-26. Retrieved from https:/ / www.jstor.org/stable/44429676

Mitnik, R., Nussbaum, M., \& Recabarren, M. (2009). Developing Cognition with Collaborative Robotic Activities. Educational Technology \& Society, 12(4), 317-330. Retrieved from https://www.jets.net/ETS/journals/12_4/27.pdf 
Mondada, F., Bonani, M., Riedo, F., Briod, M., Pereyre, L., Rétornaz, P., \& Magnenat, S. (2017). Bringing Robotics to Formal Education: The Thymio Open-Source Hardware Robot. IEEE Robotics \& Automation Magazine, 24(1), 77-85. https:/ / doi.org/10.1109/MRA.2016.2636372

Nugent, G., Barker, B., Grandgenett, N., \& Adamchuk, V. I. (2010). Impact of robotics and geospatial technology interventions on youth STEM learning and attitudes. Journal of Research on Technology in Education, 42(4), 391408. https:/ / doi.org/10.1080/15391523.2010.10782557

Nugent, G., Barker, B., Grandgenett, N., \& Welch, G. (2016). Robotics camps, clubs, and competitions: Results from a US robotics project. Robotics and Autonomous Systems, 75, Part B, 686-691. https:// doi.org/10.1016/j.robot.2015.07.011

Pa, P. S., \& Wu, C. M. (2012). Design of a hexapod robot with a servo control and a man-machine interface. Robotics and Computer Integrated Manufacturing, 28(3), 351-358. https:// doi.org/10.1016/j.rcim.2011.10.005

Park, I.W., \& Kim, J.O. (2011). Philosophy and strategy of minimalism-based user created robots (UCRs) for educational robotics-education, technology and business viewpoint. International Journal of Robots, Education and Art, 1(1), 26-38. https:// doi.org/10.4156/ijrea.vol1.issue1.3

Peppler, K. (2013). STEAM-powered computing education: Using e-textiles to integrate the arts and STEM. Computer, 46(9), 38-43. https:/ / doi.org/10.1109/MC.2013.257

Rihtaršič, D., Avsec, S., \& Kocijancic, S. (2016). Experiential learning of electronics subject matter in middle school robotics courses. International Journal of Technology and Design Education, 26(2), 205-224. https:/ / doi.org/10.1007/s10798-015-9310-7

Rockland, R., Bloom, D. S., Carpinelli, J., Burr-Alexander, L., Hirsch, L. S., \& Kimmel, H. (2010). Advancing the "E" in K-12 STEM education. Journal of Technology Studies, 36(1), 53-64. https:/ / doi.org/10.21061/jots.v36i1.a.7

Rusk, N., Resnick, M., Berg, R., \& Pezalla-Granlund, M. (2008). New pathways into robotics: Strategies for broadening participation. Journal of Science Education and Technology, 17(1), 59-69. https:/ / doi.org/10.1007/s10956-007-9082-2

Seul, J. (2013). Experiences in developing an experimental robotics course program for undergraduate education. IEEE Transactions on Education, 56(1), 129-136. https:/ / doi.org/10.1109/TE.2012.2213601

Slangen, L., van Keulen, H., \& Gravemeijer, K. (2011). What pupils can learn from working with robotic direct manipulation environments. International Journal of Technology and Design Education, 21(4), 449-469. https:/ / doi.org/10.1007/s10798-010-9130-8

Somyürek, S. (2015). An effective educational tool: construction kits for fun and meaningful learning. International Journal of Technology and Design Education, 25(1), 25-41. https:/ / doi.org/10.1007/s10798-014-9272-1

Sullivan, F. R., \& Heffernan, J. (2016). Robotic construction kits as computational manipulatives for learning in the STEM disciplines. Journal of Research on Technology in Education, 48(2), 105-128. https:/ / doi.org/10.1080/15391523.2016.1146563

Sullivan, F. R., \& Lin, X. (2012). The ideal science student: Exploring the relationship of Students' perceptions to their problem solving activity in a robotics context. Journal of Interactive Learning Research, 23(3), 1-36. Retrieved from https:// people.umass.edu/florence/jilr2.pdf

Sullivan, F. R., \& Moriarty, M. A. (2009). Robotics and discovery learning: Pedagogical beliefs, teacher practice, and technology integration. Journal of Technology and Teacher Education, 17(1), 109-142. Retrieved from https:/ / www.learntechlib.org/primary/p/26177/

Ucgul, M., \& Cagiltay, K. (2014). Design and development issues for educational robotics training camps. International Journal of Technology and Design Education, 24(2), 203-222. https:/ / doi.org/10.1007/s10798-0139253-9

Williams, D. C., Ma, Y., Prejean, L., Ford, M. J., \& Lai, G. (2008). Acquisition of physics content knowledge and scientific inquiry skills in a robotics summer camp. Journal of Research on Technology in Education, 40(2), 201216. https:/ / doi.org/10.1080/15391523.2007.10782505

Yilmaz, M., Ozcelik, S., Yilmazer, N., \& Nekovei, R. (2013). Design-oriented enhanced robotics curriculum. IEEE Transactions on Education, 56(1), 137-144. https:/ / doi.org/10.1109/TE.2012.2220775

Yuen, T. T., Boecking, M., Stone, J., Tiger, E. P., Gomez, A., Guillen, A., \& Arreguin, A. (2014). Group tasks, activities, dynamics, and interactions in collaborative robotics projects with elementary and middle school children. Journal of STEM Education: Innovations and Research, 15(1), 39-45. Retrieved from http:/ / ojs.jstem.org/index.php?journal=JSTEM\&page=article\&op=view\&path\%5B \%5D=1853 


\section{APPENDIX}

\section{Sample Questions of Integrated STEM Knowledge Test}

1. Please identify which boat is to windward and which is to downwind (leeward).
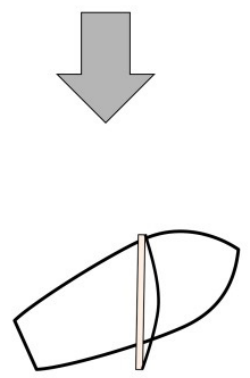

Boat A

Wind direction
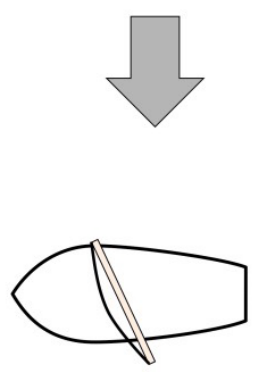

Boat B

Figure 7. Sail Direction of Boat $A$ and $B$

Boat A: windward or downwind (leeward)?

Boat B: windward or downwind (leeward)?

2. Which of the following is NOT a force acting on the sail?

A. Drag; B. lift; C. mass

3. What is the maximum amount of current for any one of the Arduino pins? Hint: check Arduino.cc under Hardware.

4. What does this function do: Serial.begin(9600)?

5. What is wrong with the following:

/ Turns an LED on for one second, then off for one second, repeatedly. This example code is in the public domain. * int led = 13;

void setup() \{

pinMode(led, INPUT);

\}

void $\operatorname{loop}()$ \{

digitalWrite(led, HIGH);

delay(1000);

digitalWrite(led, LOW);

delay(1000);

\}

6. What does GND on the board stand for and what does it mean?

7. What are the 2 essential conditions for the flow of electricity?

- Voltage Difference

- Conductive Path

8. If the weight of the boat is $160 \mathrm{gw}$, and the surface of the boat is $200 \mathrm{~cm}^{2}$, how high is the boat?

\section{http://www.ejmste.com}

